\title{
Development of a Life Cycle Inventory Dataset for Recycled Concrete Aggregates in the City of Abu Dhabi
}

\author{
Mohammed Alzard', Hilal El-Hassan', Tamer El Maaddawy ${ }^{1}$ \\ ${ }^{1}$ UAE University \\ P.O. Box 15551, Al Ain, United Arab Emirates \\ 201570286@uaeu.ac.ae; helhassan@uaeu.ac.ae; tamer.maaddawy@uaeu.ac.ae
}

\begin{abstract}
Environmental life cycle inventory (LCI) datasets are critical to conduct life cycle assessment (LCA) of concrete products. Obtaining these values from local practice is necessary to provide accurate assessment results that reflect real-life scenarios. The datasets for the recycling process of construction and demolition waste into recycled concrete aggregates (RCA) in the city of Abu Dhabi, United Arab Emirates are currently unavailable. Accordingly, this research aims to determine a detailed environmental LCI dataset for the production of RCA in Abu Dhabi. An extensive investigation of the RCA production practice was performed to highlight the input and output of each process unit. The methodology proposed by the International Standards Organization (ISO) to build an LCI (ISO 14040) was adopted. The resulting environmental LCI value for RCA production was determined to be $6.67 \times 10^{-4} \mathrm{~kg} \mathrm{CO}_{2}$ eq per kilogram of produced RCA. Research findings serve as a benchmark to evaluate the environmental sustainability of RCA and RCA-based products in a holistic LCA study, while also enriching the LCI of the city of Abu Dhabi.
\end{abstract}

Keywords: Recycled concrete aggregates, Life cycle assessment, Life cycle inventory, Construction and demolition waste.

\section{Introduction}

Recycling of construction and demolition waste (CDW) into recycled concrete aggregates (RCA) is advocated as the most suitable means of managing such waste. The process aims to reduce the burden on landfills, demand for natural aggregates (NA), and initial investment in the primary production of NA. So-produced RCA serve to provide a more sustainable replacement to NA, given their increased demand in a rapidly growing economy. In fact, recent statistics highlighted an expected $45 \%$ increase in demand for aggregates by the year 2025 [1].

Many studies have confirmed that RCA can be employed in different construction applications. Such applications include using RCA in the production of concrete [2-4], as a secondary raw material in concrete kerbs and floor blocks [5] [6], in precast concrete products [7], and as an engineering fill in the construction of roads (sub-base materials) [8]. Despite having great potential to promote environmental sustainability, the inferior performance of RCA compared to NA renders it useful in non-structural applications only. Yet, to exploit its true potential, its use should be expanded to structural applications as well. In fact, past research has been successful in developing structural concrete made with RCA [9-11]. Thus, it is clear that the performance-based qualitative assessment of RCA concrete is promising.

From an environmental feasibility perspective, it is essential to consider the burden of the recycling process to produce RCA [12]. This can be achieved by conducting a life cycle assessment (LCA) of RCA production. Many guidelines provide means and tools to conduct LCA such as the Intergovernmental Panel on Climate Change (2006 IPCC Guidelines) [13] and the International Standards Organization (ISO 14040) [14]. These methodologies provide default values in the life cycle inventory to aid in carrying out the LCA. However, these values may be inaccurate and misleading, as they are country/region-specific. As such, most guidelines emphasize on using locally developed datasets to better reflect the actual situation in the country or region. Such datasets for recycling process in the city of Abu Dhabi do not exist and should be developed to properly assess the environmental feasibility of using RCA in construction applications [15].

The aim of this research is to develop a life cycle inventory (LCI) dataset for the recycling of CDW into RCA in the city of Abu Dhabi based on current local practices. Developing these values is of critical importance, as it is the building block for conducting an LCA study for different locally-made products that may utilize RCA rather than NA. It is also essential to allow stakeholders to compare the environmental impact of NA and RCA production in Abu Dhabi. 


\section{Methodology}

To carry out this study, the methodology proposed by ISO 14040 to build an LCI was adopted [14]. Accordingly, LCI primarily consists of data collection and calculations to quantify inputs and outputs of materials and energy associated with the product system under investigation. The described operational procedure is illustrated in Fig. 1. The following sections describe the data collection and present the calculations and results.

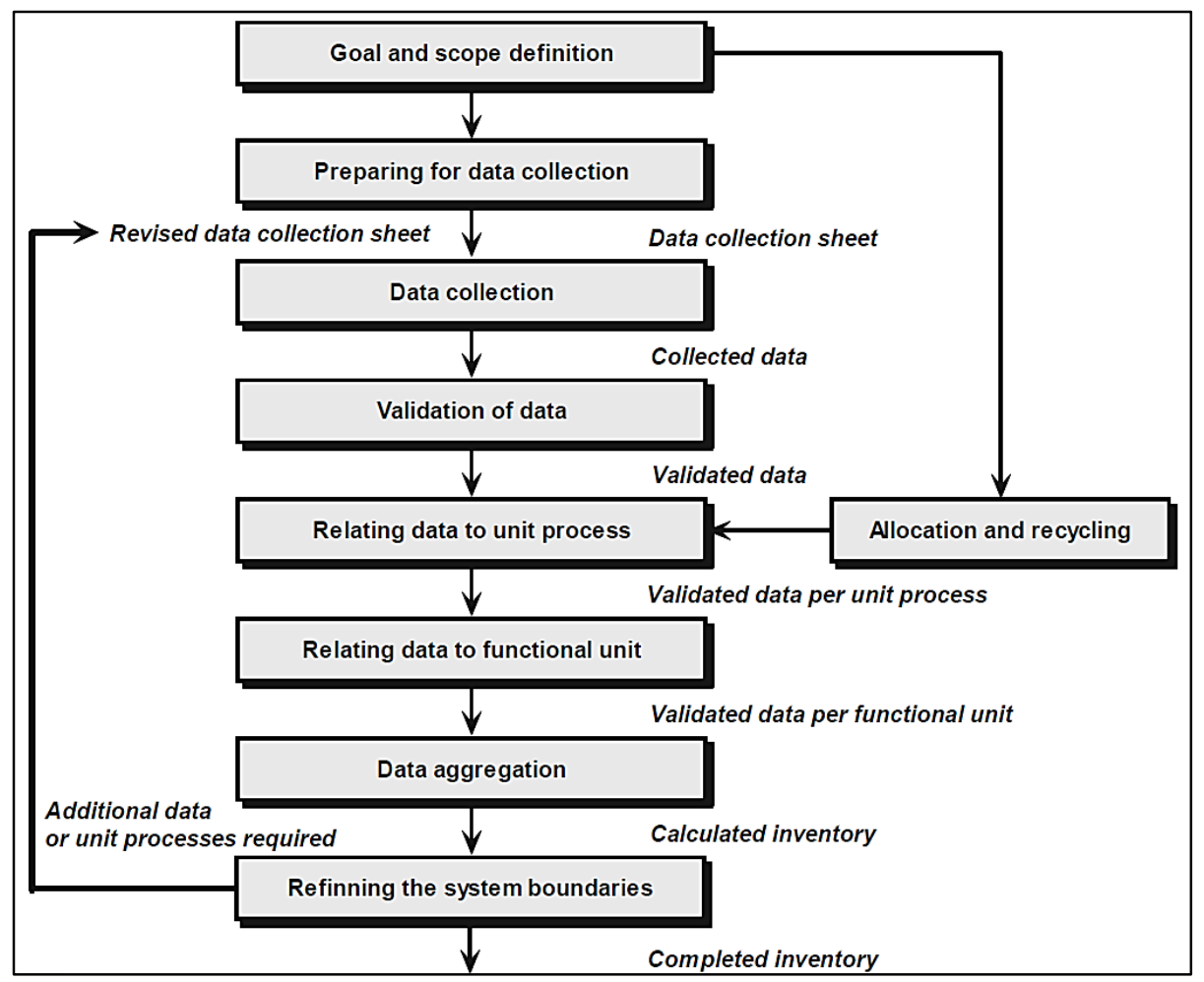

Fig. 1: Operational procedures for life cycle inventory. Adapted from [13].

\subsection{Preparation for Data Collection}

Input and output data of unit processes within the holistic process tree were identified and collected following an in-depth and detailed examination of the RCA production system. Additionally, time-related, geographical, and technological coverage were defined. To establish these parameters, a preliminary visit and examination of the site was conducted. The recycling plant under investigation is part of Al Dhafra Recycling Industries (ADRI). The plant is located $60 \mathrm{~km}$ to the south west of Abu Dhabi, the capital of the United Arab Emirates. It is the largest recycling plant in the region of Abu Dhabi by land area and handling capacity of CDW. An aerial view of the plant is shown in Fig. 2. The preliminary examination was carried out to attain a comprehensive understanding of i) the recycling process at ADRI, ii) the characteristics of the unit process under consideration, iii) the input parameters (raw materials, ancillary materials, energy, transportation) and iv) the output parameters (emissions to air, water, and land) along with their quantities.

\subsection{Data Collection and Verification}

After acquiring sufficient information from the preliminary investigation of the site, a description of the recycling process in the plant was drawn, as presented in Fig. 3. Prior to accessing the site, the truck-mounted CDW is inspected and weighed to ensure that the delivered waste confirms with the plant's requirements. After inspection, the trucks dispose of the CDW in a designated unloading area. Wheel loaders then load the waste into the feeding inlet and crushed using a jaw crusher. Subsequently, the crushed waste material is transported by means of a conveyor belt to a station 
with an overhead magnet to remove the steel and separate it from the crushed product. This steel is typically either recycled or sold as scrap metal. The conveyor belt further transports the crushed materials to a picking station, where workers manually remove any visible undesired components, such as plastic, glass, or wood, as they may negatively impact the quality of the final product. The crushed material is then forwarded via the belt to a screening station to examine its size distribution and ensure compliance to the standards. If the required size is not achieved, the material is sent to a second crushing cycle. This process ensures that the desired aggregates size is attained. From past experience, the recycling plant noticed that some relatively fine steel particles passed the first magnet. As such, a second magnet was installed to ensure any remaining steel was isolated and removed. The obtained product is sprayed with water as a dust control system and stockpiled. Figure 4 depicts the RCA after the final stage of preparation.

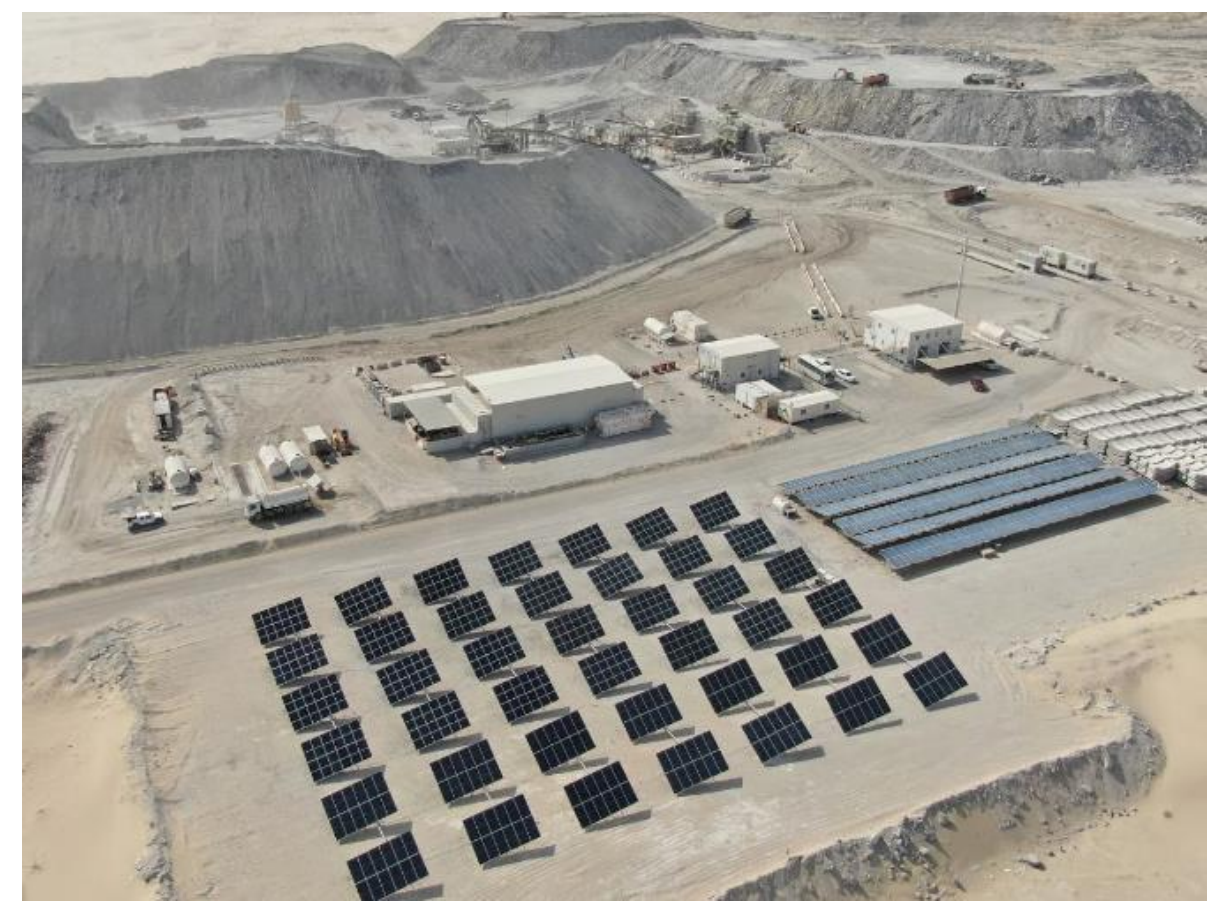

Fig. 2: Aerial view of Al Dhafra recycling plant [16].

Subsequent to setting the boundaries of the recycling process, the second step entailed the collection of data relating to the input of materials and energy and the output (such as products, co-products, and emissions) of each unit process within the RCA production process. This information was provided by ADRI recycling plant officials. It highlighted the possible sources of influence on the environmental impact of RCA. Evidently, the recycling plant processes up to 7000 tons of RCA per 12-hour work shift and consumes up to $700 \mathrm{~kW}$ of electricity per day. Nevertheless, this electricity is entirely generated by solar panels that are installed within the vicinity of the plant, as displayed in Fig. 2. Such panels are considered a renewable energy source and do not have any environmental footprint during their operation or construction phase [17]. On this basis, it was assumed that the plant did not consume energy and consequently, its environmental burden relevant to energy usage was discarded.

Furthermore, as shown in Fig. 3, part of the operations comprise several heavy machinery and equipment. They are the main contributors to the environmental impact of RCA. These diesel-run equipment operate for 12 hours per day shift to transfer the waste to the feeding inlet of the crushers and convey the final product into stockpiles and then to the delivery trucks. To calculate their environmental impact, their daily diesel consumption was calculated. Fuel consumption data were obtained from the manufacturer specifications and application handbook, considering the working load of these equipment as "medium" [18]. Based on the methodology proposed by the Intergovernmental Panel on Climate Change (IPCC) 12], to 
quantify the environmental impact of a product or a service, the impact of each activity is quantified and then multiplied by the proper emission factor, as shown in Eq. 1 [15]. In this equation, the emission factor refers to the equivalent $\mathrm{CO}_{2}$ $\left(\mathrm{CO}_{2} \mathrm{eq}\right)$ produced from the combustion of 1 liter of diesel fuel, assuming that such diesel fuel was entirely combusted without any losses. The environmental temperature and relative humidity are considered to have an insignificant effect on the emission factor [15].

Emissions $\left(\mathrm{kg} \mathrm{CO}_{2}\right.$ eq $)=\left[\right.$ Fuel Consumption Rate $\left(\frac{\mathrm{L} \text { fuel }}{\text { Equipment.h }}\right) \times$ Quantity $($ Equipment $) \times$ Duration $\left.(\mathrm{h})\right] \times$ Emission Factor $\left(\frac{\mathrm{kg} \mathrm{CO}}{2}\right.$ eq $)$

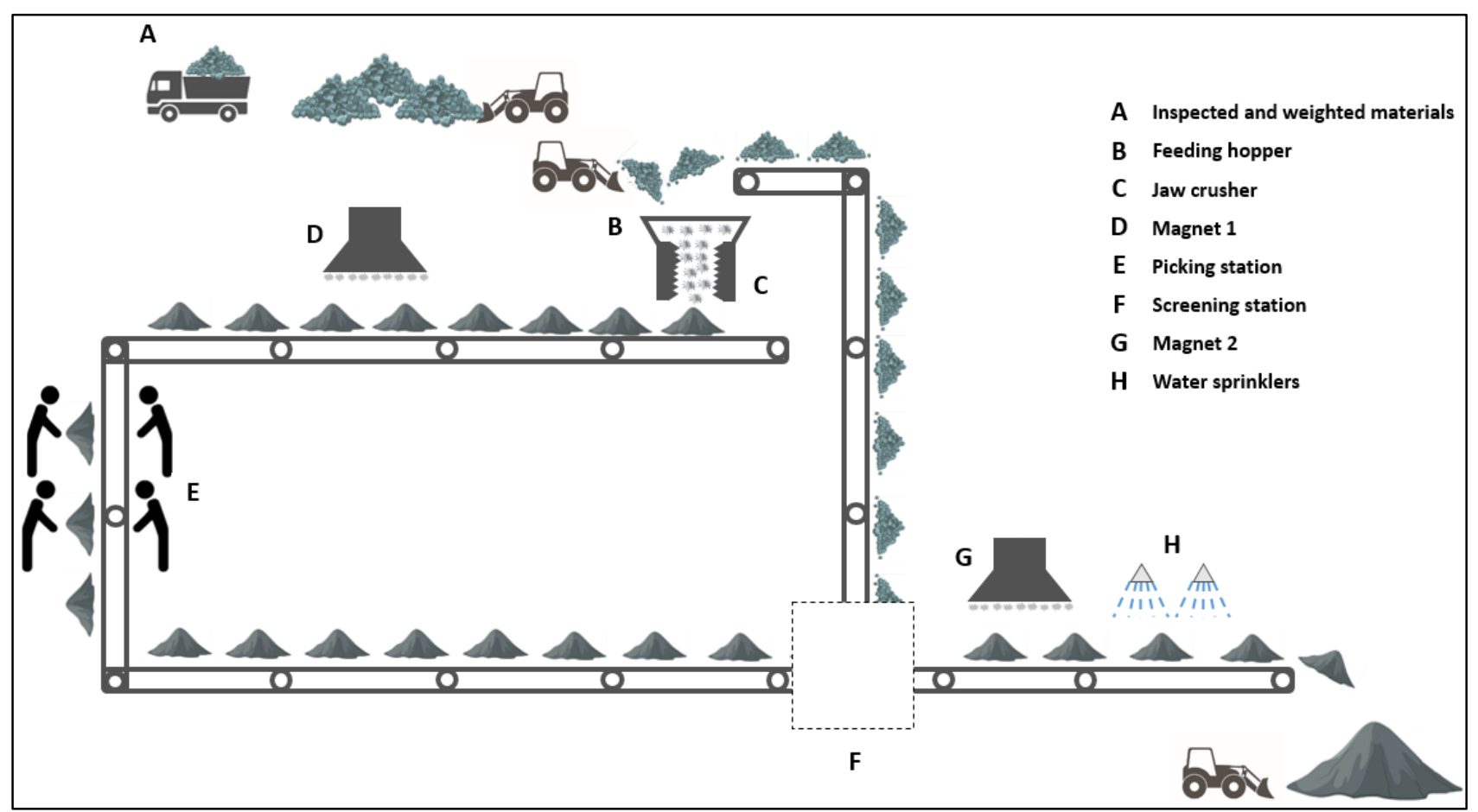

Fig. 3: Process of recycling construction and demolition waste at Al Dhafra recycling plant.

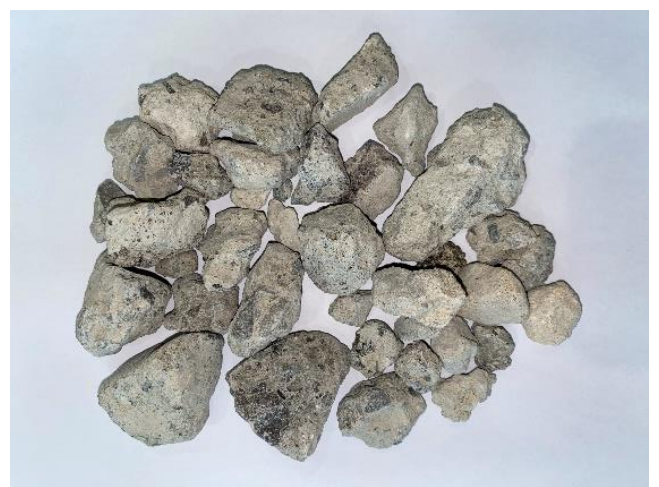

Fig. 4: Recycled concrete aggregate after the final stage of preparation.

From [13], the emission factor was found to be $2.669 \mathrm{~kg} \mathrm{CO}_{2} \mathrm{eq}$ per liter of diesel fuel consumed. Table 1 summarizes the collected data needed to quantify the environmental impact of these machineries. It should be noted that the environmental burden of the trucks used to transport the CDW to the recycling plant, i.e., demolition and 
transportation, was not accounted for, as government regulations require all demolished structures be transported to a dumpsite, which is in the vicinity of the recycling plant. In fact, CDW will have to be transported to the area, whether to be to be recycled or disposed of. As a result, the transportation of CDW from the demolition site to the recycling plan will not not contribute to the environmental impact of RCA production.

Table 1: Data to quantify the environmental impact of the equipment used in ADRI.

\begin{tabular}{llllll}
\hline Equipment & $\begin{array}{l}\text { Equipment } \\
\text { brand and model }\end{array}$ & Fuel used & $\begin{array}{l}\text { Number of } \\
\text { equipment }\end{array}$ & $\begin{array}{l}\text { Fuel consumption } \\
\text { (L/h) }\end{array}$ & $\begin{array}{l}\text { Working } \\
\text { hours (h) }\end{array}$ \\
\hline Hydraulic excavator & Komatsu PC300 & Diesel & 1 & 22.7 & 12 \\
Wheel loader & Komatsu WA470 & Diesel & 4 & 23.0 & 12 \\
& Komatsu WA500 & Diesel & 1 & 33.0 & 12 \\
\hline
\end{tabular}

\section{Results and Discussions}

The collected and verified data for the unit processes of each product were analysed to facilitate the calculation of LCI dataset for RCA production. Data related to the quantities, hourly fuel consumption, and environmental impact of the equipment were considered as the sole contributor of the environmental burden of the recycling process. The environmental impact of each equipment was calculated using Eq. 1. The results are summarized in Table 2. First, the total amount of fuel consumed by each equipment was calculated per shift depending on the brand and model, as the fuel consumption rates differ among them. Then, the obtained fuel consumption value was multiplied by the emission factor for diesel to obtain the emissions (in $\mathrm{kg} \mathrm{CO}_{2} \mathrm{eq}$ ) per shift. The emissions are then added to determine the total global warming potential associated to the use of these equipment. It was found to be a total of $4730.5 \mathrm{~kg} \mathrm{CO}_{2} \mathrm{eq}$.

The recycling plant produces 7000 tons of RCA per 12-hour shift. Accordingly, the environmental impact of producing 1 ton of RCA is the ratio of the total global warming potential (4730.5 $\mathrm{kg} \mathrm{CO}_{2} \mathrm{eq}$ ) to the total production (7000 tons), yielding $0.676 \mathrm{~kg} \mathrm{CO}_{2}$ eq $\left(6.67 \times 10^{-4} \mathrm{~kg} \mathrm{CO}_{2}\right.$ eq per $\mathrm{kg}$ of RCA). Compared to the environmental burden of typical NA production $\left(5.2 \times 10^{-3} \mathrm{CO}_{2}\right.$ eq per kg of NA [19]), that of RCA production is nearly eight times lesser. Also, the replacement of NA by RCA leads to an approximate $87 \%$ reduction in the environmental burden of aggregates. This shows that the use of RCA instead of NA is more sustainable strictly from a production standpoint. As a result, such recycled aggregates have been used in various applications, including road base and sub-base, structural fill, trench bedding, hardstand and low dust asphalt products, and foundation products. Their exclusive use in structural applications still requires further study.

Table 2: Fuel consumed by the equipment operated within the plant and the associated global warming potential (in $\mathrm{kg} \mathrm{CO}_{2} \mathrm{eq}$ ).

\begin{tabular}{llll}
\hline Equipment & $\begin{array}{l}\text { Equipment brand } \\
\text { and model }\end{array}$ & $\begin{array}{l}\text { Total amount of } \\
\text { diesel used (L/shift) }\end{array}$ & $\begin{array}{l}\text { Global warming } \\
\text { potential }(\mathbf{k g ~ C O} \mathbf{e q})\end{array}$ \\
\hline Hydraulic excavator & Komatsu PC300 & 272.4 & 727.0 \\
Wheel loader & Komatsu WA470 & 1104.0 & 2946.6 \\
& Komatsu WA500 & 396.0 & 1056.9 \\
\hline
\end{tabular}

\section{Conclusions}

The use of recycled concrete aggregates as a sustainable replacement to natural aggregates offers various environmental benefits in terms of reducing the consumption of natural resources and lessening the burden on landfills. While most research has focused on optimizing the performance of concrete products made with RCA to be comparable to NA-based counterparts, this work aimed to develop a novel, refined, and representative LCI dataset for RCA production process in the city of Abu Dhabi, United Arab Emirates. The resulting LCI value of $0.676 \mathrm{~kg} \mathrm{CO}_{2} \mathrm{eq}\left(6.67 \times 10^{-4} \mathrm{~kg} \mathrm{CO}_{2} \mathrm{eq} / \mathrm{kg}\right)$ was obtained following the methodology proposed by ISO 14040. It is eight times less than the environmental burden of producing natural aggregates, representing a reduction of approximately $87 \%$. This newly developed value will help improve the accuracy and 
overall quality of life cycle assessment studies conducted in Abu Dhabi. It will also enable stakeholders to make informed decisions on whether or not to use RCA as a more sustainable alternative to NA in various construction applications.

\section{Acknowledgements}

The authors would like to acknowledge Al Dhafra Recycling plant (ADRI) for their cooperation, support, and valuable input towards this study. The financial support of the United Arab Emirates University under grants number 31N409 and 31 N398 is also appreciated.

\section{References}

[1] R. V. Silva, J. de Brito, and R. K. Dhir, "Use of recycled aggregates arising from construction and demolition waste in new construction applications," J. Clean. Prod., vol. 236, p. 117629, 2019.

[2] D. Rodríguez-Robles, J. García-González, A. Juan-Valdés, J. M. Morán-del Pozo, and M. I. Guerra-Romero, "Quality Assessment of Mixed and Ceramic Recycled Aggregates from Construction and Demolition Wastes in the Concrete Manufacture According to the Spanish Standard," Mater., vol. 7, no. 8, pp. 5843-5857, 2014.

[3] R. V. Silva, J. de Brito, and R. K. Dhir, "Properties and composition of recycled aggregates from construction and demolition waste suitable for concrete production," Constr Build Mater., vol. 65, pp. 201-217, 2014.

[4] J. Yang, Q. Du, and Y. Bao, "Concrete with recycled concrete aggregate and crushed clay bricks," Constr. Build. Mater., vol. 25, no. 4, pp. 1935-1945, 2011.

[5] A. Klang, P.-Å. Vikman, and H. Brattebø, "Sustainable management of demolition waste — an integrated model for the evaluation of environmental, economic and social aspects," Resour. Conserv. Recy., vol. 38, no. 4, pp. 317-334, 2003.

[6] F. López Gayarre, C. López-Colina, M. A. Serrano, and A. López-Martínez, "Manufacture of concrete kerbs and floor blocks with recycled aggregate from C\&DW," Constr Build Mater., vol. 40, pp. 1193-1199, 2013.

[7] M. N. Soutsos, K. Tang, and S. G. Millard, "Use of recycled demolition aggregate in precast products, phase II: Concrete paving blocks," Constr Build Mater., vol. 25, no. 7, pp. 3131-3143, 2011.

[8] Md. U. Hossain, C. S. Poon, I. M. C. Lo, and J. C. P. Cheng, "Comparative environmental evaluation of aggregate production from recycled waste materials and virgin sources by LCA," Resour. Conserv. Recy., vol. 109, pp. 67-77, 2016.

[9] N. Kachouh, H. El-Hassan, and T. El-Maaddawy, "Effect of steel fibers on the performance of concrete made with recycled concrete aggregates and dune sand," Constr. Build. Mater., vol. 213, pp. 348-359, 2019.

[10] N. Kachouh, H. El-Hassan, and T. El-Maaddawy, "The use of steel fibers to enhance the performance of concrete made with recycled aggregate", in Fifth International Conference on Sustainable Construction Materials and Technologies (SCMT5), Kingston, UK, 2019.

[11] N. Kachouh, H. El-Hassan, and T. El-Maaddawy, "Influence of steel fibers on the flexural performance of concrete incorporating recycled concrete aggregates and dune sand," J. Sust. Cem. Based Mater., published online, pp.1-28, Aug. 2020, doi: 10.1080/21650373.2020.1809546.

[12] C. M. Mah, T. Fujiwara, and C. S. Ho, "Life cycle assessment and life cycle costing toward eco-efficiency concrete waste management in Malaysia," J. Clean. Prod., vol. 172, pp. 3415-3427, 2018.

[13] IPCC, "IPCC Guidelines for National Greenhouse Gas Inventories (2006). The Intergovernmental Panel on Climate Change." Jun-2019.

[14] ISO 14040, "Environmental management - Life cycle assessment - Principles and framework." International Organization for Standardization, 2006.

[15] M. Alzard, Maraqa, M. A., Chowdhury, R., Sherif, M., Mauga, T. I., De Albuquerque, F. B., Aljunadi, K. N., "RoadCO2: A web-based tool for estimation of greenhouse gas emissions of road projects," in IEEE Xplore digital library, Dubai - United Arab Emirates, 2019.

[16] Y. Perk, “An aerial view of Al Dhafra Recycling plant.” Google Maps, Oct-2019. 
[17] M. M. Aman, Solangi, K. H., Hossain, M. S., Badarudin, A., Jasmon, G. B., Mokhlis, H., Bakar, A. H. A., Kazi, S. N., "A review of Safety, Health and Environmental (SHE) issues of solar energy system," Renew. Sust. Energ. Rev., vol. 41, pp. 1190-1204, 2015.

[18] Komatsu, "Komatsu Specifications and Application Handbook Edition 31.” Apr-2013.

[19] CarbonSolutions, "Inventory of Carbon \& Energy (ICE) Summary." Jan-2011. 